\title{
ALTERNATIVAS À POLICIALIZAÇÃO DA SEGURANÇA PÚBLICA
}

CYNTIA CRISTINA DE CARVALHO E SILVA 


\title{
ALTERNATIVAS À POLICIALIZAÇÃO DA SEGURANÇA PÚBLICA
}

\author{
Cyntia Cristina de Carvalho e Silva ${ }^{1}$
}

\section{RESUMO}

Ao mesmo tempo em que a Constituição Federal tratou a segurança pública como um dever do Estado e responsabilidade de todos, conferiu seu exercício apenas às instituições policiais. A discussão apresentada insere-se no contexto da necessidade de se considerar a segurança pública sob uma óptica integrada, na qual se admitem em seu conceito, simultaneamente, vários elementos objetivos e subjetivos, determináveis e difusos, locais e gerais. Nesse contexto, trata-se de experiências que consideram o gerenciamento das políticas de segurança pública a partir da gestão democrática, propondo alternativas para a policialização das questões relacionadas à segurança pública.

\section{Palavras-chave:}

Segurança Pública. Criminologia. Política Criminal. Polícia.

\begin{abstract}
While defining public security as a Government duty and as a universal civic responsibility, the Federal Constitution has attributed its enforcement to police corporations. This paper is conceived in light of the perceived need to consider public security under an integrated perspective, that admit in its concept several objective and subjective elements, determinable and diffuse, local and widespread. This is the background over which are going to be discussed experiences that consider public security policies management under a democratic management approach, suggesting alternatives other than the turning of public security issues into police matters.
\end{abstract}

\section{Keywords:}

Public Security. Criminology. Criminal Policy. Police.

'Graduada em Direito pela Universidade de Brasilia. Assessora Corregedor da Justiça do Distrito Federal e Território, Pesquisadora do grupo de Pesquisa Sociedade, Controle Penal e Sistema de Justiça, da Universidade de Brasília. 


\section{O CONCEITO DE SEGURANÇA PÚBLICA NO ARTIGO 144 DA CONSTITUIÇÃO FEDERAL}

A Constituição de 1988 dedicou à segurança pública um capítulo, inserido no título referente à defesa do Estado e das instituições democráticas, restringindo seu tratamento apenas ao artigo 144:

Art. 144. A segurança pública, dever do Estado, direito e responsabilidade de todos, é exercida para a preservação da ordem pública e da incolumidade das pessoas e do patrimônio, através dos seguintes órgãos: I-policia federal;

II-policia rodoviária federal;

III-polícia ferroviária federal;

IV-polícias civis;

$V$-policias militares e corpos de bombeiros militares.

$\S 1^{\circ}$ A policia federal, instituida por lei como órgão permanente, organizado e mantido pela União $e$ estruturado em carreira, destina-se a:

$I$ - apurar infrações penais contra a ordem politica $e$ social ou em detrimento de bens, serviços e interesses da União ou de suas entidades autárquicas e empresas públicas, assim como outras infrações cuja prática tenha repercussão interestadual ou internacional e exija repressão uniforme, segundo se dispuser em lei;

II - prevenir e reprimir o tráfico ilicito de entorpecentes e drogas afins, o contrabando e o descaminho, sem prejuizo da ação fazendária e de outros órgãos públicos nas respectivas áreas de competência;

III - exercer as funções de polícia marítima, aeroportuária e de fronteiras;

IV - exercer, com exclusividade, as funções de polícia judiciária da União.

$\S 2^{\circ}$ A polícia rodoviária federal, órgão permanente, organizado e mantido pela União e estruturado em carreira, destina-se, na forma da lei, ao patrulhamento ostensivo das rodovias federais.

$\S 3^{\circ} \mathrm{A}$ policia ferroviária federal, órgão permanente, organizado e mantido pela União e estruturado em carreira, destina-se, na forma da lei, ao patrulhamento ostensivo das ferrovias federais.

$\S 4^{\circ}$ - às polícias civis, dirigidas por delegados de polícia de carreira, incumbem, ressalvada a competência da 
7.210/84 (Lei de Execuções Penais), elaborou as diretrizes da política criminal brasileira por meio da Resolução de n. 16, de 17 de dezembro de 2003, determinando princípios destinados aos Poderes Legislativos, Judiciários e Executivo.

As diretrizes do CNPCP têm como princípios, basicamente, a concepção do Direito Penal como última instância de controle social, a busca de alternativas à prisão, a humanização do sistema de justiça criminal e o compromisso com articulação e harmonização dos órgãos que compõem o sistema de justiça criminal.

Dessa forma, deve-se atribuir uma interpretação ampliada ao conceito de segurança pública na Constituição observando sua conformidade com o princípio democrático e modelo de Estado adotado pelo país. Assim, a questão da segurança pública deve ser tratada como uma ação integrada entre os poderes do Estado e a população ${ }^{3}$.

\section{OS ASPECTOS OBJETIVOS E SUBJETIVOS DA SEGURANÇAPÚBLICA}

Outro aspecto a ser avaliado na análise do caput do artigo 144 refere-se à finalidade do exercício das atividades de segurança pública, destinada à preservação da ordem pública e da incolumidade das pessoas e do patrimônio.

$\mathrm{O}$ conceito de ordem pública tem abordagem controvertida na doutrina, mas grande parte dos autores o delimita a partir das premissas que dizem respeito à prevenção e repressão à criminalidade.

É possível, contudo, considerar, nesse contexto, um significado para ordem pública que abranja, também, as idéias de efetivação dos direitos fundamentais e o aspecto dual da segurança pública, manifestados tanto na redução dos índices de criminalidade real

\footnotetext{
'DIAS NETO (2005, p. 118) esclarece ainda: "Prevenir o crime, afrontar o problema do medo, diminuir os custos sociais do crime e da reação social ao crime, garantir as condições materiais e, não meramente simbólicas, de segurança, não são tarefas que possam ser exercidas por uma única instituição, mas que requerem a co-responsabilidade do conjunto das instituições democráticas de um território: As instituições democráticas que possuem responsabilidade pelo governo de um território não podem deixar também de possuir responsabilidade pelo governo do bem público da segurança daquele mesmo território".
} 
quanto em relação à diminuição do sentimento de insegurança presente na sociedade.

Muitos criminólogos (HASSEMER, 1994; BARATTA, 2000; DIAS NETO, 2005; SOARES, 2006) abordam a questão da segurança pública no contexto da sociedade de risco, na qual a complexidade das relações sociais intensifica cada vez mais os riscos de lesões aos bens jurídicos, tornando-os, também, difusos, abrangentes, sem identificação de causas ou motivos diretos. Nessa seara, "a necessidade de minimização da insegurança por meio da previsão, identificação e administração de situações de risco converte-se em função essencial e transversal da tarefa do governo." (DIAS NETO, 2005).

A segurança pública deve ser considerada não a partir da individualização de causas ou responsabilidades, mas pela compreensão das relações causais entre conflitos e os processos sociais que o circundam. A imputação de responsabilidades individuais é questão sensível em uma realidade em que todos são, em maior ou menor grau, produtores e vítimas de situações de insegurança. Destruição ecológica, desemprego, dependência química, Aids são temas que invalidam critérios tradicionais de avaliação de causalidade para fins de mensuração das contribuições individuais pelos riscos e danos, dando margem a um quadro de impunidade geral ou de irresponsabilidade organizada. (DIAS NETO, 2005).

Dias Neto, referindo-se aos estudos de Massimo Pavarini, desenvolve um interessante raciocínio para problematizar a questão da segurança pública e a democracia.

O autor parte da complexidade das relações sociais como fator agravante no sentimento de insegurança social, propondo como solução para estabilização desse sentimento o diálogo e análise dos problemas sociais em uma abordagem ampla por meio dos canais de comunicação política. Contudo, esses canais apresentam-se cada vez mais limitados em sua capacidade de absorver e regular os conflitos, de forma que, gradualmente, os interesses em políticas de segurança pública comumente esbarram-se nos interesses de grandes grupos empresariais, econômicos, da indústria bélica ou de entretenimento.

Nesse contexto Soares alerta para a "hiper-politização" da 
segurança, a qual torna-se objeto de benefícios políticos, reforçando ainda mais a irracionalidade da cultura punitiva:

Quando me refiro à hiper-politização da segurança, quero dizer basicamente o seguinte: como os episódios cotidianos são muito dramáticos, na área da segurança, e exercem atração, fascinio e horror, simultaneamente, suscitando reações passionais da opinião pública, é natural que os políticos, acusando os gestores $e$ desgastando seu capital politico, numa perspectiva imediatista de soma-zero. [...] Freqüentemente, a crítica política é superficial, endossa os valores do senso comum, apela ao discurso conservador da ordem pública e do rigor no combate ao crime. Desse modo, em vez de contribuir para as mudanças necessárias, apenas reforçam os estereótipos e as visões que tendem a impedir as reformas e a estimular o ciclo vicioso das respostas improvisadas e voluntaristas do poder público. [...] O modelo é reativo porque estimula ações apenas depois dos fatos consumados e de acordo com pressões externas e demandas, muitas vezes, politicamente orientadas e filtradas pela mídia (que privilegia as elites e camadas médias). (....) O modelo de funcionamento policial, além de reativo, é inercial, porque tende a reproduzir padrões tradicionais, sem que haja qualquer avaliação a respeito de sua eficiência ou adequação às novas exigências da sociedade democrática e plural contemporânea. $O$ modelo é fragmentário porque são fragmentárias as demandas às quais submete as iniciativas institucionais. A hiper-politização demagógica $e$ populista tende a gerar o colapso de medidas racionais e o sacrifício da construção gradual, bem planejada, em nome do imediatismo e das respostas espetaculares, exclusivamente destinadas à repressão è èmergência." (SOARES, 2006, p. 402). (grifos aditados).

Há, portanto, um verdadeiro bloqueio dos canais democráticos de negociação de interesses e estabilização de expectativas possibilitando que soluções simbólicas do Direito Penal. "O discurso sobre os conflitos sociais converte-se em discurso sobre a criminalidade e as soluções focadas na responsabilização seletiva de indivíduos para fim de sanção. Ao invés de politizados, os problemas são policializados."(DIAS NETO, 2005). 


\section{LIDANDO COM SITUAÇÕES PROBLEMÁTICAS}

O clima de insegurança difundido na sociedade impossibilita a construção de alternativas criativas para lidar com o problema das expectativas negativas. A cultura do medo leva as pessoas a acreditarem que sempre serão a próxima vítima, devendo o Estado ou elas, por própria iniciativa, tomarem providências imediatas, ora blindando carros, trancando janelas, implantando monitoramentos eletrônicos, ora promovendo políticas de restrições de direitos fundamentais.

Uma parábola bastante recorrente, citada por Hulsman, retrata o conflito como uma "situação problemática", que, após a análise da hipótese em concreto, possui vários caminhos para solução. Cabe reproduzi-la:

Cinco estudantes moram juntos. Num determinado momento, um deles se arremessa contra a televisão e a danifica, quebrando também alguns pratos. Como reagem seus companheiros? $\dot{E}$ evidente que nenhum deles vai ficar contente. Mas, cada um, analisando o acontecido à sua maneira, poderá adotar uma atitude diferente. $O$ estudante número 2, furioso, diz que não quer mais morar como primeiro e fala em expulsá-lo de casa; o estudante número 3 declara: 'o que se tem que fazer é comprar uma nova televisão e outros pratos e que ele pague'. $O$ estudante número 4 , traumatizado com o que acabou de presenciar, grita: 'ele está doente; é preciso procurar um médico, levá-lo a um psiquiatra, etc...". O último, enfim, sussurra: 'a gente achava que se entendia bem, mas alguma coisa deve estar errada em nossa comunidade, para permitir um gesto como esse... vamos juntos fazer um exame de consciência. (HULSMAN, 1997, p. 100).

Na parábola, verifica-se que, para um mesmo fato, podem-se conferir diferentes tratamentos, resultando distintas soluções. Qualificar um fato de "crime" significa se limitar ao sistema punitivo de resposta a um conflito.-(HULSMAN, 1997).

Hulsman propõe, ainda, uma reflexão para possibilitar a associação de outros tipos de soluções para conflitos que não a utilização do sistema punitivo ao considerar crimes ou delitos como situações problemáticas. 
Considerar comportamentos socialmente negativos, a violência e o sentimento de insegurança como situações problemáticas constitui um primeiro passo para propor soluções alternativas para esses conflitos, que não a lógica da cultura do medo. (DIAS NETO, 2005).

Outro aspecto necessário na construção de políticas públicas é estabelecimento de medidas que busquem restaurar a confiança da sociedade nas diretrizes da segurança pública, de forma também a proporcionar o conhecimento da população dos planos de ação, bem como incentivar a participação na sua elaboração. Soares esclarece que:

(...) toda política de segurança pública tem que incluir uma politica de comunicação, cuja função não deverá ser a censura e o controle do medo pela mentira, mas o envolvimento da população nas políticas que visam à reconstrução das instituições e a construção da paz, oferecendo-lhe informações sobre as lógicas subjacentes às dinâmicas criminais $e$ às ações preventivas adequadas. Transparência é a melhor fórmula para restaurar a confiança. (SOARES, 2006, p. 462).

\section{ANOVAPREVENÇÃO}

Nesse contexto da necessidade dialógica no tratamento das situações problemáticas, Dias Neto (2002, p.177) apresenta uma compilação de idéias referentes à "nova prevenção", modelo que vem utilizado na Europa para tratar a questão da segurança pública. $\mathrm{O}$ autor, contudo, alerta para o risco de atribuir um único conceito para o modelo, pois cada país atribui-lhe significado distinto e até oposto, ora concentrando as diretrizes de suas políticas de segurança pública no fortalecimento do Direito Penal como, por exemplo, o "modelo da tolerância zero" e a "teoria das janelas quebradas", ora referindo-se a "policiamento comunitário", "policiamento orientado ao problema", trilhando os caminhos do direito penal mínimo. (DIAS NETO, 2005).

Basicamente todas as abordagens do modelo de nova prevenção inserem-se no contexto da abordagem da segurança pública a partir de uma perspectiva local, ou seja, realçando a necessidade de tratar 
as soluções problemáticas em nível da cidade, gerando diretrizes a uma política de segurança urbana. (BARATTA, 2000).

Dias Neto sistematiza o modelo da nova prevenção a partir de alguns conceitos chaves: interdisciplinaridade, multiagencialidade e participação.

A interdisciplinaridade é vista por meio do reconhecimento das limitações dos instrumentos do sistema penal para solucionar os conflitos sociais, os quais propõem uma leitura individualizada das causas, motivos, origem ou razões das situações problemáticas.

No contexto de uma sociedade do risco, da complexidade das relações sociais, cada vez, tornar-se mais difícil adotar a lógica da individualização de responsabilidades em temas relacionados à segurança pública, os quais envolvem, também, tanto a percepção objetiva de segurança quanto a subjetiva na proposta de soluções aos conflitos.

Assim, o conceito de segurança pública deve ser desconstruído para se admitir que não se trata apenas de uma questão de polícia ou, ainda, não se restringe ao problema do controle da criminalidade. Dias Neto pondera:

Segurança e criminalidade são conceitos apenas parcialmente interligados. $O$ trânsito, a poluição, $o$ desrespeito, a solidão, a falta de solidariedade, o preconceito, o desemprego, a midia, a pobreza, a degradação urbana, o descaso governamental são fontes cotidianas de insegurança difusa, que encontram na criminalidade um denominador comum que atua como simplificador da realidade social. (DIAS NETO, 2002, p. 78).

Dessa forma, o conceito de segurança pública deve englobar, também, idéias de insegurança difusa, provocada e reforçada, muitas vezes, por pequenas perturbações sociais ou incivilidades, que traduzem um sentimento de descaso e abandono à população.

Aniyar de Castro (2002) defende que a presença dessas incivilidades contribui para alimentar o círculo vicioso criminalidade-insegurança. A autora considera como incivilidades "más condutas", infrações ou condutas agressivas ou atemorizadoras previstas ou não nas leis, mas que nem sempre chegam a ser considerada delitos, e não são perseguidas como tais pelo Estado Punitivo. 
Essas idéias referentes à relação de incivilidades com o aumento do sentimento de insegurança devem ser analisadas, contudo, com cautela, sob pena de fundamentar a ampliação da atuação do Direito Penal e fomentar ainda mais a cultura do Estado Punitivo.

Tais incivilidades devem ser objeto de políticas públicas do Estado, não por meio de medidas destinadas ao controle social por meio do Direito Penal, mas observando alternativas e, principalmente, políticas efetivadoras dos direitos humanos.

Baratta (2000), por exemplo, ao comentar das ações do modelo da nova prevenção, apresenta um alerta bastante pertinente, lembrando que as populações mais sujeitas (ativas e passivamente) a esses tipos de incivilidades e aos efeitos do descaso do Estado são aquelas mais marginalizadas. Assim, as intervenções do Estado com vistas a se fazer presente não seriam destinadas à efetividade $\mathrm{e}$ promoção dos direitos humanos, mas sim para garantir a tranqüilidade dos "sujeitos mais socialmente protegidos". As classes ou grupos marginalizados constituiriam objetos e não sujeitos de políticas de segurança pública.

Realmente é necessário bastante cautela, pois é muito fácil utilizar o tão recorrente discurso da insegurança pública para fundamentar políticas ampliativas da atuação do sistema punitivo como, por exemplo, implantação de monitoramento eletrônicos nas cidades, de controle do cumprimento de medidas ou penas alternativas por meio de aparelhos eletrônicos ou, melhor, "coleiras," dentre outras. Impõe-se, então, o questionamento: com essas providências, quem teria direito ao sentimento de segurança?

Bustos Ramirez explica que a política criminal do Estado Democrático de Direito deve considerar, em primeiro lugar, como realidade e não apenas um programa, o princípio da igualdade, de forma que não apenas alguns teriam direito ao sentimento de segurança e efetividade dos direitos fundamentais, mas todos.

Considerando o modelo do Estado Democrático de Direito, DIAS NETO (2005) observa a necessidade de se compatibilizar o respeito a regras comuns de civilidade com o exercício da diversidade como pressuposto de uma gestão democrática, lembrando das diferenças culturais existentes na população. Assim, "ao contrário de uma proposta centrada na exclusão, na imposição 
coativa da 'tolerância zero' em relação a valores desviantes ou estilos de vida minoritários, o que se alvitra é um modelo de máxima tolerância urbana que possa servir de sustentação a uma segurança socialmente fundada".

Admitir o conflito é premissa básica para o desenvolvimento de qualquer noção de segurança pública no Estado Democrático de Direito, pois a democracia pressupõe o conflito e a diversidade de interesses, como bem lembrou Morin:

A democracia supõe e nutre a diversidade dos interesses, assim como a diversidade de idéias. $O$ respeito à diversidade significa que a democracia não pode ser identificada como a ditadura da maioria sobre as minorias; deve comportar o direito das minorias e dos contestadores à existência e à expressão, e deve permitir a expressão das idéias heréticas e desviantes. [...] A democracia necessita ao mesmo tempo de conflitos de idéias e de opiniões, que lhe conferem sua vitalidade e produtividade. [...] A democracia constitui, portanto, um sistema político complexo, no sentido de que vive de pluralidades, concorrências e antagonismos, permanecendo como comunidade. Assim, a democracia constitui a união entre a união $e$ a desunião; tolera e nutre-se endemicamente, às vezes explosivamente, de conflitos que lhe conferem vitalidade. Vive da pluralidade, até mesmo na cúpula do Estado (divisão dos poderes executivo, legislativo, judiciário), e deve conservar a pluralidade para conservar-se a si própria. (MORIN, 2007, pp. 108-109). (grifos aditados).

Admitir o conflito e também a pluralidade de pensamentos, ideologia e focos de poderes na sociedade é garantir a existência de um Estado Democrático de Direito. Administrar essas relações conflituosas, estabelecendo parâmetros de atuação e controle do Estado é matéria afeta às políticas de segurança pública, sob o enfoque apresentado.

Outro conceito importante para o modelo da nova prevenção é o de multiagencialidade, que, na verdade, já decorre do contexto de interdisciplinaridade.

Quando se analisa a questão da segurança pública a partir da noção de situações problemáticas e não apenas reduzindo o conflito em objeto exclusivo do sistema penal, conclui-se que a constituição 
de uma rede de prevenção e estratégia em relação à segurança pública não deve estar necessariamente centrada no eixo policial. "A multiagencialidade pressupõe que o tema da segurança deixe de ser visto como 'questão de polícia', para converter-se em 'questão de política'."'(DIAS NETO, 2002).

A multiagencialidade, nos moldes da nova prevenção, pressupõe atribuir ao direito penal função residual, para que ele não ocupe o espaço de outras medidas preventivas necessárias e não seja considerado a única resposta possível e imediata à questão.

É necessário também levar em conta que o conceito de segurança pública não é reduzido apenas ao combate da criminalidade. Assim, Baratta (2000) defende a aplicação do direito penal mínimo como sinônimo de direito penal constitucional, devendo atuar apenas em casos de graves violações de direitos fundamentais.

Dessa forma, os conceitos de multiagencialidade e de interdisciplinaridade também interferem nas diretrizes da atuação policial sob a óptica do modelo da nova prevenção, de modo a promover um policiamento comunitário e orientado ao problema. "Na qualidade de ator necessário, mas não suficiente para a produção da segurança, a polícia passa por profundas transformações organizacionais, operacionais e culturais voltadas a torná-la mais integrada ao ambiente externo e, por conseqüência, mais apta a compreender a realidade em que atua e a prestar bons serviços". (DIAS NETO, 2005).

Sobre o policiamento comunitário, ANIYAR DE CASTRO (2002) explica tratar-se de uma nova filosofia policial, de patrulha, em substituição à polícia profissional, baseada em normas rígidas para ação e atividades sumárias, que trabalha no interior de seus departamentos, apresentando-se à comunidade apenas quando era chamada a impor a ordem ou determinada pelas diretrizes de seus chefes. O policiamento comunitário admite uma polícia mais livre e criativa, em contato com a comunidade para escutar as prioridades locais antes de atuar. A própria polícia abandonaria as velhas práticas com fundamento no sistema punitivo para adotar alternativas a responder as situações problemáticas.

Finalmente, o último conceito chave do modelo de prevenção social, apresentado por Dias Neto, refere-se à participação da 
sociedade civil no planejamento da segurança da cidade. Essa perspectiva abrange, também, a idéia da vigilância comunitária, na qual membros de organizações locais (comerciantes, residentes) reúnem-se, com apoio da polícia comunitária, para criação de redes de segurança para fins de observação e proteção local.

Fundamental levar em conta que a participação comunitária nas políticas de segurança pública deve ser pautada, necessariamente, por princípios democráticos, admitindo, acima de tudo, que uma convivência pacífica comunitária não corresponde a uma sociedade sem conflitos. Mas incluir a participação da sociedade civil representa, contudo, alguns riscos.

Um deles refere-se à possibilidade de a comunidade local, em virtude da preservação do sossego público, organizar-se contra pequenos grupos, impedindo-os de exercer seus direitos fundamentais, adotando-se, na maioria das vezes, uma postura intolerante às diferenças. Tal postura, ao invés de constituir mecanismos visando à implantação do sentimento de segurança social, pode acabar promovendo animosidades entre grupos e produzindo um sentimento de alarme coletivo em relação às condutas delituosas.

Dessa forma, é preciso cautela e muita consciência acerca dos objetivos propostos para aplicação do modelo da nova prevenção na elaboração de políticas públicas, sob pena de qualquer atitude precipitada, sem planejamento e delimitação de finalidades constituir medida para fundamentar ainda mais a lógica punitiva.

\section{CONCLUSÃo}

A discussão apresentada insere-se no contexto da necessidade de se considerar a segurança pública sob uma óptica integrada, na qual se admitem, simultaneamente, vários elementos objetivos e subjetivos, determináveis e difusos, locais e gerais no seu conceito.

Trata-se, ainda, de questão bastante delicada, pois envolve interesses particulares de diferentes grupos sociais, mas, ao mesmo tempo, diz respeito a toda sociedade.

Partindo dessas análises, observa-se que o tratamento conferido à segurança pública no artigo 144 da Constituição não é compatível com os parâmetros e discussões sobre a matéria, pois, restringe, 
basicamente, a atuação e exercício da segurança pública às agências policiais.

Todavia, é possível, a partir de uma interpretação ampliada da Constituição Federal, com base nos princípios do Estado Democrático de Direito considerar a questão da segurança pública como a busca da estabilização das expectativas positivas em relação à promoção da ordem pública, considerada sob uma óptica democrática, e da vigência de uma sociedade cooperativa, atuando ao lado do Estado na administração dos conflitos e definição de soluções para as situações problemáticas.

\section{REFERÊNCIAS BIBLIOGRÁFICAS}

ANIYAR DE CASTRO, Lola Aniyar de. La Participation Ciudadana en la Prevención del Delito: Antecedentes, Debates y Experiencias. Comités de Seguridad Vecinales. In: Disertación en Jornadas de debate para el aporte a la discusión de la Política Criminal organizada. Ministerio de Justicia y la Secretaria de Política Criminal, Penitenciaria y de Readaptación Social em la Secretaria de Ciência y Técnica, 2000.

BARATTA, Alessandro. Criminologia Crítica e Crítica do Direito Penal: introdução à sociologia do direito penal. Trad. de Juarez Cirino dos Santos. $3^{\mathrm{a}}$ ed. Rio de Janeiro: Editora Revan: Instituto Carioca de Criminologia, 2002.

. La Politica Criminal y el Derecho Penal de la Constitución: nuevas reflexiones sobre el modelo integrado de las ciencias penais. Revista Brasileira de Ciências Criminais. São Paulo: Revista dos Tribunais, 2000. Vol. 29. Ano 8. pp. 30-49.

BUSTOS RAMIREZ, Juan Bustos. Política criminal Y Estado. Disponível em www.cienciaspenales.org/REVISTA\%2012/BUSTOS12.htm Acesso em 28-11-2007.

DIAS NETO, Theodomiro. A Nova Prevenção: uma política integrada de segurança urbana. In: ANDRADE, Vera Regina Pereira 
de. (org) Verso e reverso do controle penal: (Des)aprisionando a sociedade da cultura punitiva. Homenagem a Alessandro Baratta. Florianópolis: Fundação Boiteux, 2002.

. Segurança urbana: o modelo da nova prevenção. São Paulo: Editora Revista dos Tribunais: Fundação Getúlio Vargas, 2005.

HUlSMAN, Louk e CELIS, Jacqueline Bernat de. Penas perdidas: $\mathrm{o}$ sistema penal em questão. Trad. Maria Lucia Karan. $2^{\mathrm{a}}$ ed. Rio de Janeiro: Editora LUAM, 1997.

MORIN, Edgar. Os sete saberes necessários à educação do futuro. Trad. Catarina Eleonora F. da Silva e Jeanne Sawaya. $12^{\mathrm{a}}$ ed. São Paulo: Cortez, 2007.

SILVA, José Afonso da. Curso de Direito Constitucional Positivo. $28^{\mathrm{a}}$ ed. rev. Atual. São Paulo: Malheiros, 2007.

SOARES, Luis Eduardo. Legalidade Libertária. Rio de Janeiro: Editora Lumen Juris, 2006. 